\title{
Relationship between biological age, body dimensions and cardiorespiratory performance in young soccer players
}

\author{
Bettina Béres ${ }^{\bowtie}$, István Györe, Leonidas Petridis, Katinka Utczás, Irina Kalabiska, Gergely Pálinkás, and Tamás Szabó \\ Research Centre for Sport Physiology, University of Physical Education, Budapest, Hungary
}

\begin{abstract}
Background: During adolescence, performance in competitive sport is influenced not only by the levels of physical activity, but also by the biological state and body dimensions. Objective: The purpose of our study was to compare cardiorespiratory performance between groups with different biological age in male adolescent soccer players. Methods: Eighty-eight young soccer players (age $=15.9 \pm 0.5$ years, body height $=176.1 \pm 5.6 \mathrm{~cm}$, body weight $=65.4 \pm 7.2 \mathrm{~kg}$ ) performed a vita-maxima protocol on a treadmill. Starting speed was $6 \mathrm{~km} / \mathrm{h}$ and inclination 1.4\%, which were increased linearly every minute, to $11 \mathrm{~km} / \mathrm{h}$ and to $3.5 \%$ respectively (first 5 minutes). Then we increased inclination by $2 \%$ every minute until exhaustion. The effect of the biological age on functional indices was examined based on two grouping methods. First, the participants were classified into sub-groups by their morphological (or developmental) age, which is an expression of biological age and evaluates the developmental state of specific body dimensions (body height, body weight, shoulder width, lower arm girth, and hand circumference). Then, from anthropometric and body composition measures three clusters were created, according to the participants' developmental state. For both grouping methods, the groups were: latematuring, average-maturing, early-maturing. Results: Based on the morphological age grouping method, biologically more advanced athletes achieved greater cardiorespiratory performance (late-maturing: $337 \pm 33 \mathrm{~W}$, average maturing: $363 \pm 48 \mathrm{~W}$, early maturing: $386 \pm 43 \mathrm{~W}$ ) with higher oxygen uptake (late-maturing: $3529 \pm 336 \mathrm{ml} / \mathrm{min}$, average-maturing: $3798 \pm 436 \mathrm{ml} / \mathrm{min}$, early-maturing: $3983 \pm 541 \mathrm{ml} / \mathrm{min}$ ) and oxygen pulse (late-maturing: $18.1 \pm 1.8 \mathrm{ml} /$ beat, average-maturing: $19.6 \pm 2.5 \mathrm{ml} /$ beat, early-maturing: $20.8 \pm 2.8 \mathrm{ml} /$ beat). There were no differences in time spent on the treadmill, maximal lactic acid levels, relative power, maximal heart rate, respiratory rate, tidal volume, relative maximal oxygen uptake, maximal ventilation. There were significant differences in weight, plastic index and muscle mass between all the three groups. Differences in cardiorespiratory indices between groups of different maturity status were larger when we grouped the athletes based on cluster analysis compared to the morphological age-based grouping method. Conclusions: During growth and maturation Body dimensions and body (and muscle) mass significantly affect maximal oxygen uptake in young athletes. The inclusion of body composition components in addition to body dimensions increases the explanatory power of biological age on cardiorespiratory performance.
\end{abstract}

Keywords: maturity, spiroergometry, oxygen uptake, cluster analysis, football

\section{Introduction}

In soccer, players have to meet significant physical, technical, tactical and mental expectations (Stølen et al., 2005). Fitness requirements during official competitions include a high level of aerobic and anaerobic capacities. Depending on their playing position, the players cover approximately 10-13 kilometres with varying intensity, averaging $85-98 \%$ of their maximum heart rate and $70 \%$ of their maximum oxygen uptake during a single game (Bangsbo et al., 2006). Measurements indicate that both aerobic and anaerobic metabolic pathways contribute significantly to performance during the match (Alghannam, 2012; Redkva et al., 2018). Thus, existing evidence suggests that an advanced cardiorespiratory system is an important element of game performance at the elite level (Chamari et al., 2005).
Helgerud et al. (2001) showed that an increase in maximal oxygen uptake $\left(\mathrm{VO}_{2 \max }\right)$ may improve the tactical and technical performance of the players by $7 \%$. This also means more efficient ball contacts and more and longer sprints during a game (Chamari et al., 2005).

It has been well established that body dimensions (i.e., body weight, body height, shoulder width, chest circumference) significantly affect cardiorespiratory performance, and strong correlations have been reported between cardiorespiratory indicators and anthropometric measures (Osborne et al., 1992).

The role of body dimensions in cardiorespiratory endurance is more relevant in adolescents (Ostojic et al., 2014). According to Liyanage and Jayamanne (2017) body height, chest circumference and fat-free mass predict respiratory parameters in children aged 8-16 years. Previous results also suggest that there is a strong positive relationship

$\triangle$ Corresponding author: Bettina Béres, e-mail tanczos.bettina@tf.hu

Article history: Received 3 August 2020, Accepted 5 January 2020, Published 10 March 2021

Copyright: ( 2021 The Author(s). Published by Palacký University Olomouc. This is an open access article distributed under the terms of the Creative Commons Attribution License (https://creativecommons.org/licenses/by/4.0/), which permits unrestricted use, distribution, and reproduction in any medium, provided the original author and source are credited. This license does not cover any third-party material that may appear with permission in the article. 
between chest circumference and resting maximum ventilation volume (Shekar \& Brashier, 2017).

Given the significant differences that can be observed in the timing and tempo of growth among young players (Beunen et al., 2006; Malina et al., 2012) the importance of body dimensions becomes even more profound. Typically, these differences favour early maturing children in youth soccer, who generally have better physical fitness scores and may outperform their less mature peers at different selection levels. This may also result in potentially talented, but late-maturing players, having fewer training and competition opportunities and fewer chances to reach the elite level (Ostojic et al., 2014). In light of this, biological maturity must be taken into account when assessing aerobic performance in young players (Carvalho et al., 2013; Guimarães et al., 2019; Welsman et al., 1996).

A commonly used method to assess the biological age of children in Hungary is the estimation of the morphological age (Mészáros \& Mohácsi, 1983; Mészáros et al., 2000). This is an indicator of somatic development and it relies on the measurement of actual body dimensions, namely height, weight, shoulder width, lower arm girth, and hand circumference (Bodzsár, 2000; Mészáros \& Mohácsi, 1983).

Therefore, the aim of this study was to compare cardiorespiratory performance between groups with different biological age. Biological status assessment and grouping the athletes according to their maturity state (early-maturing, average-maturing and late-maturing) was performed using two methods. First, we used the morphological age as an expression of biological age and second, we used a cluster analysis including anthropometric and body composition variables. It was also our aim to compare cardiorespiratory performance between groups of different maturity according to both grouping methods separately.

\section{Methods}

Participants

Eighty-eight young soccer players (age $=15.9 \pm 0.5$ years, body height $=176.1 \pm 5.6 \mathrm{~cm}$, body weight $=65.4 \pm 7.2$ $\mathrm{kg}$ ) participated in the study. All players were registered athletes at Hungarian Soccer Academies. At the time of the measurements, players had been playing soccer for an average of $9.9 \pm 2.1$ years and their training load was on average $9.2 \pm 1.9$ hours per week with an official match on weekends. Players were informed in advance of the nature of the measurements, their course and risks, and their parents/guardians gave written consent to perform the measurements. The Research Ethics Committee of the University of Physical Education approved this research (TE-KEB/No40/2019).

\section{Anthropometry}

Athletes' body dimensions (body height, body weight, lower arm girth, hand circumference, upper arm girth, thigh circumference, calf circumference, chest circumference, shoulder width, triceps skinfold, subscapular skinfold, thigh skinfold, abdominal skinfold, calf skinfold) were collected by standardized methods (Martin \& Saller, 1957). Measurements were performed in the morning hours (8.00-9.00 a.m.).

\section{Morphological age}

The players' biological state was estimated by morphological age (or developmental age), as described by Mészáros et al. (1985). Briefly, this method is based on the measurement of the following anthropometric variables: body height, body weight, and plastic index (arithmetic sum of the shoulder width, lower arm girth and hand circumference; Conrad, 1963). Individual values by sex and age group are compared to normative values from the Hungarian population and an equivalent age for each variable is then assigned to an accuracy of 0.25 year. Morphological age is estimated by calculating the mean of chronological age and the three age equivalents of body height, body weight and plastic index (Mészáros et al., 1985). The normative database was modified to follow changes due to the secular trend by Mészáros et al. (2006) and by Bodzsár et al. (2011). Subgroups of the different developmental stage were formed based on the difference between chronological and morphological age. Similarly to previous research (Ostojic et al., 2014), average-matures included athletes with a difference of \pm 0.5 years between their morphological and chronological age. Early-maturing group included athletes whose morphological age was at least half a year older than their chronological age, while the late-maturing group included those, whose morphological age was at least half a year below their chronological age.

\section{Body composition}

Athletes' body composition was estimated using regression equations based on the four-component Drinkwater-Ross model (fat mass, muscle mass, skeletal mass, residual mass) (Drinkwater \& Ross, 1980). Of these, the study included fat and muscle mass, body fat percent and muscle mass percent.

\section{Spiroergometry}

Cardiorespiratory endurance was measured with a spiroergometry test on a treadmill (WOODWAY PPS Med; WOODWAY Inc., Waukesha, WI, USA). The intensity of the exercise was increased linearly every minute until $\mathrm{VO}_{2 \max }$ criteria were achieved (increase in $\mathrm{VO}_{2} \leq 2.1 \mathrm{ml} / \mathrm{kg} / \mathrm{min}$ with an increase in workload, maximum heart rate $>95 \%$ of the age-estimated maximum heart rate) and subjective signs and symptoms were observed too (Rowland, 2017). Vmax Encore 29c analyser (SensorMedics Corporation, Palm Springs, CA, USA) was used to measure gas exchange parameters. The $\mathrm{VO}_{2 \max }$ was determined from the average of twelve breaths. Measurements were made in the daily hours (between about 10:00 a.m. and 1:00 p.m.). The temperature at the laboratory was about $22^{\circ} \mathrm{C}$, and the relative humidity between $25-35 \%$. The study included the following variables: time spent on treadmill (s), maximum lactic acid levels $(\mathrm{mmol} / \mathrm{L})$, maximum heart rate (beats per minute $[\mathrm{bpm}])$, maximum ventilation $(\mathrm{L} / \mathrm{min})$, respiratory rate $(\mathrm{L} / \mathrm{min})$, tidal volume $(\mathrm{L})$, maximal $\mathrm{CO}_{2}$ emissions $\left(\mathrm{VCO}_{2 \max } ; \mathrm{ml} / \mathrm{min}\right), \mathrm{VO}_{2 \max }(\mathrm{ml} / \mathrm{min})$, relative $\mathrm{VO}_{2 \max }$ 
$(\mathrm{ml} / \mathrm{min} / \mathrm{kg})$, maximal oxygen pulse (ml/beat). Additionally, maximum power (W) and relative maximum power $(\mathrm{W} / \mathrm{kg}$ ) was extracted from the gas analyser software using the following two formulas.

In the first two load steps: power $[\mathrm{W}]=($ speed $[\mathrm{km} / \mathrm{h}] *$ body weight $[\mathrm{kg}] *$ $(2.05+0.29 *$ TAN (slope) * 100) $-0.6 *$ body weight $[\mathrm{kg}]-151) / 10.5$

In the following steps: power $[\mathrm{W}]=($ speed $[\mathrm{km} / \mathrm{h}] *$ body weight $[\mathrm{kg}] *$

$(2.11+0.25 *$ TAN(slope $) * 100)-2.2 *$ body weight $[\mathrm{kg}]-151) / 10.5$

\section{Statistical analysis}

Values are expressed as $M \pm S D$. To test normality, we used the Kolmogorov-Smirnov test and the Levene's test for the homogeneity of variance. We used one-way analysis of variance for the effect of group assessment and Tukey posthoc for groups comparison. Additionally, we performed a hierarchical cluster analysis using all components of the morphological age supplemented with chest circumference and body composition indicators (muscle mass, body fat, percentage of muscle mass, percentage of body fat). Then, three groups of different biological state (late-maturing, average-maturing, and early-maturing) were formed. Effect sizes were tested using $\eta$ and $\eta^{2}$. $\eta$ indicates the strength of the relationship between individual variables (Lakens, 2013); values of $\eta<.39$ were accepted as weak, between $.40-.69$ as moderate, and > .70 as strong (Cohen, 1988). $\eta^{2}$ was used to quantify the between-groups effect size comparisons (Lakens, 2013). Significance level was set at $p<.05$. Data were analysed using SPSS software (Version 19.0; IBM, New York, NY, USA).

\section{Results}

Distribution for maximal heart rate, absolute and relative power, ventilation, breathing frequency, tidal volume, absolute and relative $\mathrm{VO}_{2 \max }$ and oxygen pulse followed a normal distribution. Levene's test for the equality of variance was not violated for any of the examined variables. Based on morphological age, $21(23.9 \%)$ athletes were in the late-maturing group, 47 (53.4\%) in the average-maturing group and $20(22.7 \%)$ in the early-maturing group. There was no significant effect in decimal age and height, while there were significant differences in body weight and plastic index between all the three groups. Post-hoc comparisons showed higher values for the more advanced group compared to the less advanced group. The results also revealed significantly larger muscle mass for the early-matures compared to the average and late-matures. However, there were no differences in muscle mass and body fat mass in relation to the body weight, more specifically in the percentage of muscle mass (\%) and percentage of body fat (\%). Chest circumference showed significant differences between all three groups. Descriptive values of anthropometric data for each group are presented in Table 1.

Descriptive values of the cardiorespiratory variables by maturity status are presented in Table 2. There were no significant effects of maturity state in the time spent on the treadmill, maximal lactic acid levels, relative power, maximal heart rate, respiratory rate, tidal volume, relative $\mathrm{VO}_{2 \max ,}$ maximal ventilation. Post hoc comparison showed differences between the early and late-maturing groups in power, $\mathrm{VCO}_{2 \max }, \mathrm{VO}_{2 \max }$, and maximum oxygen pulse.

Grouping based on cluster analysis resulted in fewer athletes being assigned to the early-maturing group, compared to the grouping method based on morphological age. More specifically, 37 athletes $(42.0 \%)$ were in the late-maturing group, $37(42.0 \%)$ in the average-maturing group and 14 $(16.0 \%)$ in the early-maturing group. Descriptive values of the anthropometric and body composition variables are shown in Table 3.

Tables 4 and 5 include $\eta$ and $\eta^{2}$ values for the anthropometric and cardiorespiratory values, respectively. Both $\eta$ and $\eta^{2}$ increased for the cluster analysis-based grouping method compared to the morphological age-based grouping.

\section{Discussion}

In this study, we investigated the effect of biological age and body dimensions on functional cardiorespiratory parameters in young football players. We tested the effects of two methods used to estimate maturity status, the one using anthropometric measures (Bodzsár et al., 2011; Mészáros et al., 2006; Mészáros \& Mohácsi, 1983), and the other using anthropometric and body composition measures. Such data may contribute to our understanding concerning the role of biological status in cardiorespiratory performance.

Table 1 Descriptive values $(M \pm S D)$ and intergroup comparisons of anthropometric and body composition variables by morphological age

\begin{tabular}{|c|c|c|c|c|c|c|}
\hline \multirow[b]{2}{*}{ Variable } & \multirow[b]{2}{*}{$\operatorname{LM}(n=21)$} & \multirow[b]{2}{*}{ AM $(n=47)$} & \multirow[b]{2}{*}{$\mathrm{EM}(n=20)$} & \multicolumn{3}{|c|}{$p$} \\
\hline & & & & $\mathrm{LM} \times \mathrm{AM}$ & $\mathrm{LM} \times \mathrm{EM}$ & $\mathrm{AM} \times \mathrm{EM}$ \\
\hline Decimal age (year) & $15.9 \pm 0.5$ & $15.9 \pm 0.5$ & $15.9 \pm 0.5$ & .80 & .98 & .90 \\
\hline Body height $(\mathrm{cm})$ & $175.6 \pm 4.1$ & $176.4 \pm 5.9$ & $176.0 \pm 6.3$ & .95 & .98 & .10 \\
\hline Body weight (kg) & $60.0 \pm 3.8$ & $65.8 \pm 7.4$ & $70.0 \pm 5.6$ & .004 & $<.001$ & .05 \\
\hline Plastic index $(\mathrm{cm})$ & $80.9 \pm 2.3$ & $84.2 \pm 3.2$ & $86.6 \pm 2.5$ & $<.001$ & $<.001$ & .008 \\
\hline Muscle mass (kg) & $26.1 \pm 1.9$ & $28.7 \pm 3.1$ & $30.3 \pm 2.7$ & .01 & $<.001$ & .04 \\
\hline Percentage of muscle mass (\%) & $44.7 \pm 1.5$ & $45.0 \pm 1.3$ & $44.9 \pm 1.6$ & .21 & .82 & .59 \\
\hline Percentage of body fat (\%) & $10.7 \pm 1.7$ & $10.9 \pm 1.9$ & $10.7 \pm 1.8$ & .23 & .85 & .58 \\
\hline Chest circumference $(\mathrm{cm})$ & $82.9 \pm 3.2$ & $86.4 \pm 5.0$ & $89.5 \pm 2.4$ & .006 & $<.001$ & .03 \\
\hline
\end{tabular}

Note. $\mathrm{LM}=$ late-maturing; $\mathrm{AM}=$ average-maturing; $\mathrm{EM}=$ early-maturing. 
Table 2 Descriptive values $(M \pm S D)$ and intergroup comparisons of spiroergometric variables by morphological age

\begin{tabular}{|c|c|c|c|c|c|c|}
\hline \multirow[b]{2}{*}{ Variable } & \multirow[b]{2}{*}{$\operatorname{LM}(n=21)$} & \multirow[b]{2}{*}{ AM $(n=47)$} & \multirow[b]{2}{*}{$\operatorname{EM}(n=20)$} & \multicolumn{3}{|c|}{$p$} \\
\hline & & & & $\mathrm{LM} \times \mathrm{AM}$ & $\mathrm{LM} \times \mathrm{EM}$ & $\mathrm{AM} \times \mathrm{EM}$ \\
\hline Time spent on treadmill (s) & $567 \pm 40$ & $562 \pm 36$ & $569 \pm 50$ & .90 & .98 & .80 \\
\hline Maximum lactic acid levels (mmol/L) & $9.8 \pm 2.5$ & $9.7 \pm 2.4$ & $10.0 \pm 2.5$ & .98 & .95 & .87 \\
\hline Power (W) & $337 \pm 33$ & $363 \pm 48$ & $386 \pm 43$ & .05 & $<.001$ & .05 \\
\hline Relative power (W/kg) & $5.6 \pm 0.4$ & $5.5 \pm 0.4$ & $5.5 \pm 0.5$ & .75 & .99 & .85 \\
\hline Maximum heart rate (bpm) & $195 \pm 7.0$ & $194 \pm 7.1$ & $192 \pm 9.7$ & .89 & .28 & .38 \\
\hline Maximum ventilation (L/min) & $111 \pm 12$ & $119 \pm 14$ & $121 \pm 17$ & .08 & .08 & .91 \\
\hline Respiratory rate (L/min) & $55.3 \pm 5.7$ & $56.2 \pm 7.1$ & $55.5 \pm 6.4$ & .86 & .10 & .85 \\
\hline Tidal volume (L) & $2.0 \pm 0.2$ & $2.1 \pm 0.3$ & $2.2 \pm 0.4$ & .28 & .12 & .68 \\
\hline $\mathrm{VCO}_{2 \max }(\mathrm{ml} / \mathrm{min})$ & $3958 \pm 406$ & $4237 \pm 521$ & $4500 \pm 562$ & .10 & .002 & .12 \\
\hline $\mathrm{VO}_{2 \max }(\mathrm{ml} / \mathrm{min})$ & $3529 \pm 336$ & $3798 \pm 436$ & $3983 \pm 541$ & .06 & .01 & .31 \\
\hline Relative $\mathrm{VO}_{2 \max }(\mathrm{ml} / \mathrm{min} / \mathrm{kg})$ & $58.9 \pm 5.6$ & $58.1 \pm 5.2$ & $57.2 \pm 6.3$ & .82 & .41 & .63 \\
\hline Maximum oxygen pulse (ml/beat) & $18.1 \pm 1.8$ & $19.6 \pm 2.5$ & $20.8 \pm 2.8$ & .06 & .002 & .18 \\
\hline
\end{tabular}

Note. $\mathrm{LM}=$ late-maturing; $\mathrm{AM}=$ average-maturing; $\mathrm{EM}=$ early-maturing; $\mathrm{bpm}=$ beats per minute; $\mathrm{VCO}_{2 \max }=\operatorname{maximal} \mathrm{CO}_{2}$ emissions; $\mathrm{VO}_{2 \max }=\operatorname{maximal}$ oxygen uptake.

Table 3 Descriptive values $(M \pm S D)$ of anthropometric and body composition variables by morphological age and cluster analysis grouping methods

\begin{tabular}{|c|c|c|c|c|c|c|}
\hline \multirow[b]{2}{*}{ Variable } & \multicolumn{2}{|c|}{ Late-maturing } & \multicolumn{2}{|c|}{ Average-maturing } & \multicolumn{2}{|c|}{ Early-maturing } \\
\hline & $\operatorname{BMA}(n=21)$ & BCA $(n=37)$ & BMA $(n=47)$ & $\mathrm{BCA}(n=37)$ & $\operatorname{BMA}(n=20)$ & $\mathrm{BCA}(n=14)$ \\
\hline Decimal age (years) & $15.9 \pm 0.5$ & $15.8 \pm 0.5$ & $15.9 \pm 0.5$ & $15.9 \pm 0.5$ & $15.9 \pm 0.5$ & $16.1 \pm 0.5$ \\
\hline Body height $(\mathrm{cm})$ & $175.6 \pm 4.1$ & $172.0 \pm 3.8$ & $176.4 \pm 5.9$ & $177.5 \pm 4.2$ & $176.0 \pm 6.3$ & $183.3 \pm 3.5$ \\
\hline Body weight (kg) & $60.0 \pm 3.8$ & $59.4 \pm 3.2$ & $65.8 \pm 7.4$ & $66.6 \pm 3.3$ & $70.0 \pm 5.6$ & $77.7 \pm 3.9$ \\
\hline Plastic index $(\mathrm{cm})$ & $80.9 \pm 2.3$ & $81.4 \pm 2.2$ & $84.2 \pm 3.2$ & $84.9 \pm 2.1$ & $86.6 \pm 2.5$ & $88.2 \pm 3.5$ \\
\hline Muscle mass (kg) & $26.1 \pm 1.9$ & $25.8 \pm 1.5$ & $28.7 \pm 3.1$ & $29.2 \pm 1.2$ & $30.3 \pm 2.4$ & $33.4 \pm 2.1$ \\
\hline Percentage of muscle mass (\%) & $44.7 \pm 1.5$ & $44.8 \pm 1.3$ & $45.0 \pm 1.3$ & $45.2 \pm 1.3$ & $44.9 \pm 1.6$ & $44.4 \pm 1.8$ \\
\hline Percentage of body fat (\%) & $10.7 \pm 1.7$ & $10.6 \pm 1.6$ & $10.9 \pm 1.9$ & $10.4 \pm 1.3$ & $10.7 \pm 1.8$ & $12.4 \pm 2.6$ \\
\hline Chest circumference $(\mathrm{cm})$ & $82.9 \pm 3.2$ & $82.8 \pm 2.9$ & $86.4 \pm 5.0$ & $87.2 \pm 2.6$ & $89.5 \pm 2.4$ & $92.8 \pm 4.6$ \\
\hline
\end{tabular}

Note BMA $=$ based on morphological age; $\mathrm{BCA}=$ based on cluster analysis .

Table $4 \eta$ and $\eta^{2}$ values of the morphological age and cluster analysis grouping methods for anthropometric and body composition variables

\begin{tabular}{lcccccc}
\hline & \multicolumn{2}{c}{$\begin{array}{c}\text { Based on } \\
\text { morphological age }\end{array}$} & & \multicolumn{2}{c}{$\begin{array}{c}\text { Based on } \\
\text { cluster analysis }\end{array}$} \\
\cline { 2 - 3 } \cline { 5 - 6 } Variable & $\eta$ & $\eta^{2}$ & & $\eta$ & $\eta^{2}$ \\
\hline Decimal age & .06 & .00 & & .17 & .03 \\
Body height & .06 & .00 & & .72 & .52 \\
Body weight & .48 & .23 & & .89 & .79 \\
Plastic index & .57 & .33 & & .72 & .51 \\
Muscle mass & .48 & .24 & & .88 & .77 \\
Percentage of muscle mass & .07 & .01 & & .19 & .04 \\
Percentage of body fat & .05 & .00 & & .39 & .15 \\
Chest circumference & .49 & .24 & & .75 & .56 \\
\hline
\end{tabular}

Based on our experience and on literature data (Osborne et al., 1992; Welsman et al., 1996) body dimensions have a significant role in cardiorespiratory performance, especially with regards to the maximal oxygen uptake.

It is well established that the type of training affects aerobic capacity. Athletes from endurance-type sports demonstrate generally higher oxygen uptake than athletes from team sports or strength-type sports. Aerobic capacity in soccer is an essential requirement in-game performance, therefore its development from a young age seems
Table $5 \eta$ and $\eta^{2}$ values of the morphological age and cluster analysis grouping methods for spiroergometric variables

\begin{tabular}{lccccc}
\hline & \multicolumn{2}{c}{$\begin{array}{c}\text { Based on } \\
\text { morphological age }\end{array}$} & & \multicolumn{2}{c}{$\begin{array}{c}\text { Based on } \\
\text { cluster analysis }\end{array}$} \\
\cline { 2 - 3 } \cline { 5 - 6 } Variable & $\eta$ & $\eta^{2}$ & & $\eta$ & $\eta^{2}$ \\
\hline Time spent on treadmill & .08 & .01 & & .11 & .01 \\
Power & .37 & .13 & & .72 & .51 \\
Relative power & .08 & .01 & & .12 & .01 \\
Maximum heart rate & .15 & .02 & & .10 & .01 \\
Maximum ventilation & .26 & .07 & & .56 & .32 \\
Respiratory rate & .06 & .00 & & .12 & .01 \\
Tidal volume & .22 & .05 & & .59 & .34 \\
VCO $_{2 \max }$ & .35 & .12 & & .68 & .47 \\
VO $_{2 \max }$ & .34 & .12 & & .61 & .37 \\
Relative VO $_{2 \max }$ & .11 & .01 & & .37 & .13 \\
Maximum & .36 & .13 & & .59 & .35 \\
\hline
\end{tabular}

Note. $\mathrm{VCO}_{2 \max }=$ maximal $\mathrm{CO}_{2}$ emissions; $\mathrm{VO}_{2 \max }=$ maximal oxygen uptake.

necessary. On average, elite soccer players have maximal oxygen uptake around $56.8-67.6 \mathrm{ml} / \mathrm{kg} / \mathrm{min}$ (Arnason et al., 2004). Oxygen uptake values in our sample were similar to those reported by Valente-dos-Santos et al. (2014). Their sample included 81 healthy male soccer players aged 8-18 years of European (Caucasian) ancestry. Despite the differences in the testing protocols oxygen uptake values were similar. Participants in the study of Valente-dos-Santos et al. started running at $7.9 \mathrm{~km} / \mathrm{hr}$ with subsequent increments of $0.72 \mathrm{~km} / \mathrm{hr}$ and had no inclination at all $\left(\mathrm{VO}_{2 \max }\right.$ was 
$3.33 \pm 0.47(\mathrm{~L} / \mathrm{min})$ at the age of $13-15$, and $3.83 \pm 0.40$ (L/min) at the age of 16-18). Our protocol included lower velocity, but higher inclination producing however similar oxygen uptake values.

Our results were consistent with previous studies, where body dimensions (Valente-dos-Santos et al., 2014), body mass (Cunha et al., 2011) including muscle mass and maturity status (Armstrong et al., 2019) affected aerobic performance. Morphological age is an expression of biological age, which includes body dimension measures, so we divided the athletes into three groups of the different developmental stage to examine the effects of this type of biological age on performance indices. Not surprisingly, the mean values of the three groups not only differed in their structural characteristics, but also differed in functional indices, like power, $\mathrm{VCO}_{2 \max }, \mathrm{VO}_{2 \max }$, or maximum oxygen pulse. These results are in line with findings of Guimaráes et al. (2019), who reported higher body height and larger body mass for early matures. In our sample, body height did not differ between the groups. A possible explanation for this may be that at this age (15-16 years) children (including late-matures) have reached more than $92 \%$ of their adult height, which means that their body height does not change significantly anymore. Thus, differences due to variations in growth and maturation decrease resulting in similar body height for either early or late-matures may have. It may also indicate that body height in soccer is not a selection criterion, as it is for example in other team sports (i.e., basketball, handball). Advanced maturity here is expressed mostly with more developed musculature and larger girth and width measures. Since ventilation was similar in all groups (there was no difference in either respiratory rate or tidal volume), the differences in oxygen uptake were attributed to the larger body weight and more specifically, to the larger muscle mass. This confirms previous reports supporting that during adolescence, the increase in absolute oxygen uptake is closely related to changes in muscle mass (Armstrong \& Welsman, 2019; Rowland, 2005).

Despite the differences in absolute values, there were no differences in relative values (e.g., relative power or relative $\left.\mathrm{VO}_{2} \max \right)$. These results have two indications. First, that at this age range, changes in cardiovascular performance follow changes in body weight and muscle mass, which makes it difficult to isolate the effects of natural biological development from the effects of training adaptation. And second, that when late-maturing athletes catch up to the normal- or early-maturing athletes, differences in cardiorespiratory function will most likely diminish. This again highlights the importance of considering biological age in talent identification and in the selection process during adolescence preventing in this way disappointment and early drop out for late-maturing athletes.

The statistical analysis revealed that the differences between the groups according to their morphological age were mainly observed in the late-maturing group. Due to their smaller body dimensions and to their lower body mass and muscle mass, these athletes had lower values in absolute power and oxygen uptake. Such differences in maturation may generate a disadvantage for late-maturing athletes and can lead to their exclusion during talent selection (Fiander et al., 2014). This once more highlights the need for biological age to be considered in performance evaluation. Supporting this, Ostojic et al. (2014) reported that in adult elite football, $60.1 \%$ of players are from late-matures, $38.1 \%$ normal and only $11.8 \%$ from an early-maturing group, therefore it is important to pay attention to keeping late-maturing athletes in sport.

An interesting approach was to examine the effects of the biological state including body composition components next to anthropometric measures. The results suggest that the relationship between anthropometric and spiroergometric variables became stronger with the use of the cluster analysis. This was confirmed by the $\eta$ values. Higher $\eta^{2}$ values refer to a higher power for the cluster analysis and indicate that the groups formed by cluster analysis were more distinct from each other than the groups formed on the basis of morphological age. It also indicates that maturity state as defined by the cluster analysis can explain a higher percentage of the variance in either anthropometric or cardiorespiratory variables compared to the maturity groups defined by the morphological age. Higher explanatory power is most likely attributed to the inclusion of body composition variables, which suggests that body composition components should be included when relating biological maturity to cardiorespiratory performance.

The main limitation of this study is the lack of a control group with non-athletes. In this way, we could compare the results of the soccer and non-athletes groups by their biological state, which could provide a wider understanding of the body dimensions' importance in cardiorespiratory functions. The main question in such studies is the quantification of the effects coming from training adaptation and from natural development. However, the nature of the collected data lacks specificity for such analysis. To examine training adaptation exact training data are necessary. Unfortunately, we had no data on the training regimes of the athletes. It should be noted, however, that since participants were members of different clubs, thus having different training schedule, the collection of such data became technically challenging.

\section{Conclusions}

Our results confirm the significance of biological development in the evaluation of cardiorespiratory performance in male adolescent soccer players. The values draw the attention to interpret carefully $\mathrm{VO}_{2 \max }$ values, as are closely related to body characteristics. In the evaluation of cardiorespiratory performance according to differences in biological maturity, our findings suggest the inclusion of body composition components, in an attempt to increase the explanatory power of biological age.

\section{Conflict of interest}

The authors report no conflict of interest. 


\section{References}

Alghannam, A. F. (2012). Metabolic limitations of performance and fatigue in football. Asian Journal of Sports Medicine, 3(2), 65-73. https://doi.org/10.5812/ asjsm.34699

Armstrong, N., Tomkinson, G. R., \& Ekelund, U. (2019). Aerobic fitness and its relationship to sport, exercise training and habitual physical activity during youth. British Journal of Sports Medicine, 45(11), 849-858. https://doi. org/10.1136/bjsports-2011-090200

Armstrong, N., \& Welsman, J. (2019). Development of peak oxygen uptake from 11-16 years determined using both treadmill and cycle ergometry. European Journal of Applied Physiology, 119(3), 801-812. https://doi.org/10.1007/ s00421-019-04071-3

Arnason, A., Sigurdsson, B. S., Gudmunksson, A., Holme, I., Engebretsen, L., \& Bahr, R. (2004). Physical fitness, injuries, and team performance in soccer. Medicine \& Science in Sports \& Exercise, 36(2), 278-285. https://doi org/10.1249/01.mss.0000113478.92945.ca

Bangsbo, J., Mohr, M., \& Krustrup, P. (2006). Physical and metabolic demands of training and match-play in the elite football player. Journal of Sports Sciences, 24(7), 665-674. https://doi.org/10.1080/02640410500482529

Beunen, G. P., Rogol, A. D., \& Malina, R. M. (2006). Indicators of biological maturation and secular changes in biological maturation. Food and Nutrition Bulletin, 27(4, Suppl. 5), S244-S256. https://doi.org/10.1177/15648265060274s508

Bodzsár, É. (2000). A review of Hungarian studies on growth and physique of children. Acta Biologica Szegediensis, 44(1-4), 139-153.

Bodzsár, É., Zsákai, A., \& Pápai, J. (2011). A Mészáros-Mohácsi-féle morfológiai életkor becslés antropometriai táblázatainak modifikálása [The modification of the anthropometric tables for morphological age estimation created by Mészáros and Mohácsi.. Anthropologiai Közlemények, 52, 109-117. https://epa. oszk.hu/03100/03120/00070/pdf/EPA03120 anthropologiai kozlemenyek 52 109-117.pdf

Carvalho, H. M., Coelho-e-Silva, M. J., Eisenmann, J. C., \& Malina, R. M. (2013) Aerobic fitness, maturation, and training experience in youth basketball. International Journal of Sports Physiology and Performance, 8(4), 428-434. https:// doi.org/10.1123/iispp.8.4.428

Chamari, K., Hachana, Y., Kaouech, F., Jeddi, R., Moussa-Chamari, I., \& Wisløff, U. (2005). Endurance training and testing with the ball in young elite socce players. British Journal of Sports Medicine, 39(1), 24-28. https://doi.org/10.1136/ bjsm.2003.009985

Cohen, J. (1988). Statistical power analysis for the behavioral sciences (2nd ed.) Lawrence Erlbaum Associates. https://doi.org/10.4324/9780203771587

Conrad, K. (1963). Der Konstitutionstypus [The constitution type]. Springer.

Cunha, G., Lorenzi, T., Sapata, K., Lopes, A. L., Gaya, A. C., \& Oliveira, Á. (2011) Effect of biological maturation on maximal oxygen uptake and ventilatory thresholds in soccer players: An allometric approach. Journal of Sports Sciences, 29(10), 1029-1039. https://doi.org/10.1080/02640414.2011.570775

Drinkwater, D. T., \& Ross, W. D. (1980). Anthropometric fractionation of body mass. In M. Ostyn, G. Beunen, \& Simons, J. (Eds.), Kinanthropometry II (pp. 178-189). University Park Press.

Fiander, M., Jones, M. I., \& Parker, J. K. (2014). Coaches' perceptions of the use of chronological and biological age in the identification and development of talented athletes. In R. Schinke (Ed.), Innovative writing in sport and exercise psychology (pp. 147-163). Nova Science Publishers.

Guimarães, E., Ramos, A., Janeira, M. A., Baxter-Jones, A. D. G., \& Maia, J. (2019). How does biological maturation and training experience impact the physical and technical performance of 11-14-year-old male basketball players? Sports, 7(12), Article 243. https://doi.org/10.3390/sports 7120243
Helgerud, J., Engen, C. L., Wisloff, U., \& Hoff, J. (2001). Aerobic endurance training improves soccer performance. Medicine \& Science in Sport \& Exercise, 33(11), 1925-1931. https://doi.org/10.1097/00005768-200111000-00019

Lakens, D. (2013). Calculating and reporting effect sizes to facilitate cumulative science: A practical primer for t-tests and ANOVAs. Frontiers in Psychology, 4, Article 863. https://doi.org/10.3389/fpsyg.2013.00863

Liyanage, G., \& Jayamanne, B. D. (2017). Prediction of spirometry parameters using chest circumference in Sri Lankan boys aged 8-16 years. Journal of Health and Social Sciences, 2(3), 273-278.

Malina, R. M., Coelho, E. S. M. J., Figueiredo, A. J., Carling, C., \& Beunen, G. P. (2012). Interrelationships among invasive and non-invasive indicators of biological maturation in adolescent male soccer players. Journal of Sports Sciences, 30(15), 1705-1717. https://doi.org/10.1080/02640414.2011.639382

Martin, R., \& Saller, K. (1957). Lehrbuch der anthropologie I-IV [Textbook of Anthropology I-IV]. Gustav Fisher Verlag.

Mészáros, J., Mészáros, Z., Zsidegh, M., Prókai, A., Vajda, I., Photiou, A., \& Mohácsi, J. (2006). Nemzedékenkénti növekedési különbségek és utánpótlás-nevelés [Differences in secular trend and youth sport]. Magyar Sporttudományi Szemle, 27, 3-6.

Mészáros, J., \& Mohácsi, J. (1983). A biológiai fejlettség meghatározása és a felnőtt termet elörejelzése a városi fiatalok fejlödésmenete alapján [Determinin the biological development and prediction of adult height based on the development of urban youth]. Hungarian Academy of Sciences.

Mészáros, J., Mohácsi, J., Szabó, T., \& Szmodis, I. (1985). Assessment of biological development by anthropometric variables. In R. A. Binkhorst, H. C. G. Kemper, \& W. H. M. Saris (Eds.), Children and Exercise XI (pp. 341-345). Human Kinetics. Mészáros, J., Mohácsi, J., Szabó, T., \& Szmodis, I. (2000). Anthropometry and competitive sport in Hungary. Acta Biologica Szegediensis, 44(1-4), 189-192.

Osborne, G., Wolfe, A. L., Burggraf, W. G., \& Norman, R. (1992). Relationships between cardiac dimensions, anthropometric characteristics and maximal aerobic power ( $\mathrm{VO}_{2} \max$ ) in young men. International Journal of Sports Medicine, 13(3), 219-224. https://doi.org/10.1055/s-2007-1021257

Ostojic, S. M., Castagna, C., Calleja-González, J., Igor, J., Idrizovic, K., \& Stojanovic, M. (2014). The biological age of 14-year-old boys and success in adult soccer: Do early maturers predominate in the top-level game? Research in Sports Medicine, 22(4), 398-407. https://doi.org/10.1080/15438627.2014.944303

Redkva, P. E., Paes, M. R., Fernandez, R., \& da-Silva, S. G. (2018). Correlation between match performance and field tests in professional soccer players. Journal of Human Kinetics, 62, 213-219. https://doi.org/10.1515/hukin-2017-0171 Rowland, T. W. (2005). Children's exercise physiology (2nd ed.). Human Kinetics. Rowland T. W. (Ed.). (2017). Cardiopulmonary exercise testing in children and adolescents. Human Kinetics.

Shekar, A., \& Brashier, D. B. (2017). A study to assess the co-relation between chest circumference and maximum voluntary ventilation in healthy adults. Indian Journal of Basic and Applied Medical Research, 6(2), 265-270. https:// www.ijbamr.com/assets/images/issues/pdf/March\%202017\%20265-270.pdf.pdf

Stølen, T., Chamari, K., Castagna, C., \& Wisløff, U. (2005). Physiology of soccer. Sports Medicine, 35(6), 501-536. https://doi.org/10.2165/00007256-200535060-00004

Valente-dos-Santos, J., Coelho-e-Silva, M. J., Tavares, O. M., Brito, J., Seabra, A. Rebelo, A., Sherar, B. L., Elferink-Gemser, T. M., \& Malina, R. M. (2014). Allometric modelling of peak oxygen uptake in male soccer players of 8-18 years of age. Annals of Human Biology, 42(2), 126-134. https://doi.org/10.3109/03014 460.2014.932007

Welsman, R. J., Armstrong, N., Nevill, M. A., Winter, M. E., \& Kirby, J. B. (1996). Scaling peak $\mathrm{VO}_{2}$ for differences in body size. Medicine \& Science in Sports \& Exercise, 28(2), 259-265. https://doi.org/10.1097/00005768-199602000-00016 